\title{
Effect of locally applied vibration on pain reduction in patients with chronic low back pain: A pilot study
}

\author{
Hana Bednáŕíková ${ }^{1, *}$, David Smékal', Pavlína Krejčiříková², and Ivana Hanzlíková1 \\ ${ }^{1}$ Faculty of Physical Culture, Palacký University Olomouc, Olomouc, Czech Republic; and ${ }^{2}$ Centre of Rehabilitation, Hospi- \\ tal Prostějov, Prostějov, Czech Republic
}

Copyright: (c) 2018 H. Bednářiková et al. This is an open access article licensed under the Creative Commons Attribution License (http://creativecommons.org/licenses/by/4.0/).

\begin{abstract}
Background: Locally applied vibration has been recently proposed as a treatment for pain relief. Objective: The aim of this study was to assess the effect of specific vibration therapy using the Redcord Stimula device on reduction of pain in patients with chronic low back pain. Methods: The study included 14 subjects aged 16-59 years. Pain was assessed at the baseline and after the therapy using the Short Form McGill Pain Questionnaire as well as with Oswestry Disability Index, pressure pain thresholds were recorded by a mechanical algometer. All subjects received 8 therapy sessions, each session consisting of 7 proprioceptive exercises adapted for use in the Redcord suspension system with the Redcord Stimula device. Results: After completing the therapy, a statistically significant reduction in the pain score was recorded in both questionnaires. The average values decreased by $8.8 \%(p=.001)$ in the Short Form McGill Pain Questionnaire and by 7.6\% $(p=.001)$ in the Oswestry Disability Index. Pain thresholds measured by an algometer showed statistically significant increase in 3 of 5 measured sites. Conclusions: The results of the study suggest that locally applied vibration may be a viable option for treatment of chronic pain.
\end{abstract}

Keywords: pain treatment, Redcord Stimula, vibration therapy

\section{Introduction}

Chronic pain represents a severe problem in the society, it is reflected not only in the field of medicine, but also in economic and social areas (Opavský, 2011). Up to $80 \%$ of the adult population experience low back pain during their lifetime. In this case, we can talk about some sort of civilization "disease" associated with the modern way of life of long-term sedentary activity and lack of exercise. The causes of low back pain are numerous, and they are often combined. Functionally, these are mostly joint blockage, muscle imbalance, hypermobility or pain transferred from internal organs. The structural causes are mainly degenerative changes in spine, trauma, congenital or acquired deformities and some diseases such as Bechterew's disease, osteoporosis or bone metastases (Skála, Effler, Herle, Fila, 2011).

The term "nonspecific chronic low back pain" describes a painful condition lasting for more than

\footnotetext{
* Address for correspondence: Hana Bednáríiková, Department of Natural Sciences in Kinanthropology, Faculty of Physical Culture, Palacký University Olomouc, třída Míru 117, 77111 Olomouc, Czech Republic. E-mail: bednarikova25@seznam.cz
}

three months when the pathology of anatomical structures is not evident, and the exact cause of the pain is unknown (Opavský, 2011).

Treatment of chronic pain is very important. The main goal of treatment is to alleviate pain intensity and ensure sufficient quality of sleep and improvement in physical and mental performance. A multidisciplinary approach - pharmacotherapy, physiotherapy, psychosocial support - is important for the treatment of chronic low back pain. An integral part is the motivation of patients to improve their health (Opavský, 2011).

Local (regional) vibrations are not a common part of the treatment of chronic pain. Vibrations were previously used primarily in diagnostics to determine the severity, quality and level of disability of the nervous system (Pfeiffer, 2007). In routine practice, vibration is most commonly encountered as an evaluation tool in diagnostics of alternations of deep sensation within the neurological examination.

From the point of view of effect, vibration is a mechanical stimulus. Its effect on skeletal muscle is complex, it affects not only the muscle itself, but it also affects the entire central nervous system (Pavlů \& Strachotová, 2011). From the neurophysiological point 
of view, vibration is perceived most by the primary ending of muscle spindle. This receptor perceives the low intensity vibrations as well as vibration of up to 220 Hz. However, the activation of the primary endings of muscle spindles is not linear (Burke, Hagbarth, Lofstedt, \& Wallin, 1976).

The vibration in pain therapy is based on the main principle of gate control theory of pain (Rittweger, 2010). The optimum vibration frequency for the use of gate control theory of pain is about $100 \mathrm{~Hz}$. Lower frequency vibrations do not have a greater analgesic effect but are more likely to increase motor output. Similar results are presented by Loewenstein and Skalak (1966), according to which the optimal vibration frequency for an analgetic effect is higher than $90 \mathrm{~Hz}$.

Roy, Hollins, and Maixner (2003) applied vibrations at $20 \mathrm{~Hz}$ and $100 \mathrm{~Hz}$ in individuals with temporomandibular joint pain. In this study it was found that higher statistically significant pain-relieving effects were only found in vibrations with higher frequency.

Norwegian physiotherapists, the authors of the therapeutic concept Neurac - Neuromuscular activation, use the "analgetic effect of vibration". The system Neurac has been developed to treat chronic pain in the musculoskeletal system. The causes of chronic pain are lack of the coordination of muscle activity and reduced proprioception in the area of pain (Muceli, Farina, Kirkesola, Katch, \& Falla, 2010). The Neurac therapy used the application of vibration to increase the afferentation of the patient's body segment. However, in the scientific literature there is lack information about the effect of locally applied vibration without using methods and principles Neurac therapy.

Thus, the aim of this study was to evaluate the effect of local vibration (produced by Redcord Stimula) to influence pain levels in patients with non-specific chronic low back pain.

\section{Methods}

\section{Participants}

A total of 14 subjects with chronic low back pain were included in the study. It consisted of 10 women and 4 men. Age was $38.21 \pm 14.19$ years (range 16-59 years). The subjects were selected based on primary diagnosis nonspecific chronic low back pain. The diagnosis had to be determined by a treating physician. The research was approved by the Ethics Committee of the Faculty of Physical Culture, Palacký University Olomouc. All subjects signed informed consent.

The main criterion for inclusion of the subjects to the study was chronic low back pain lasting more than 3 months without a structural basis. In the case of 5 subjects, pain was localized only in the low back area, in the case of 2 subjects the pain was also transmitted to the buttocks, in the case of 4 subjects around the groin and hip joints and in the case of 3 subjects to the thoracic spine and the shoulder blade.

The exclusion criteria were a structural basis of low back pain, such as diagnosis of spinal canal stenosis, radicular irritation, spondylolisthesis and spondylolysis or inborn spinal defects (spina bifida) and an undergoing spine surgery or hip joint and lower extremities surgery involving implantation of metallic material. The last criterion of exclusion was the application of needling to any of the subjects during 3 months prior to the rehabilitation.

In the case of all subjects, physical therapy and medication use primarily affecting pain was excluded during the research because of possible distortion of the results of the study.

\section{Procedures}

Two questionnaires were filled in during the initial examination: Short Form McGill Pain Questionnaire (SF-MPQ) and Oswestry Disability Index (ODI). The SF-MPQ is often used in clinical practice, capturing not only the intensity but also the character of the pain (Rokyta, Kršiak, \& Kozák, 2012). It also includes Present Pain Intensity Scale and Visual Analog Scale (VAS). The ODI is a questionnaire used in individuals with chronic low back pain focusing on pain and limitation of activities of daily living. It quantifies subjective disability of the individual and expresses the rate of disability (Savre, 2011). Furthermore, detailed anamnesis was taken, and an initial kinesiology examination focused on the area of a pelvis and lower extremities were performed. Information and data from anamnesis and kinesiology examination were used only for the control of physiotherapist during rehabilitation. Two tests on the functional state of deep spinal stabilization system (diaphragmatic test and the flexion of the hip, ankle and knee joint test - Kolář \& Lewit, 2005) were also conducted. Then measurement using a pressure algometer (Wagner Instruments, Greenwich, CT, USA) was performed. In the low back area, 5 places in the paravertebral muscle areas at the level of L1, L2, L3, L4, and L5 were defined 2-3 cm from the vertebrae spinous processes, which are the same for each subject. These places were defined only for use in this study after the consultation with the neurologist. Both sides of the spine were measured, the research considered only the data corresponding to the side with greater pain.

After undergoing a series of eight therapies the final examination was performed in both groups. Both questionnaires were filled in again and the tests on the 
functional state of deep spinal stabilization system (diaphragmatic test and the flexion of the hip, ankle and knee joint test) were carried out. The measurement of the pressure algometry at the same places on the side of the spine chosen according to stronger pain during the initial examination was repeated.

In the study, the evaluator and the therapist were the same person.

\section{Intervention}

The study included 8 units of therapy using a Redcord Stimula device (Redcord AS, Staubø, Norway). The Redcord Stimula device (Figure 1) is a set of three motors embedded in special plastic case generating controlled vibration. The device can be easily attached and removed from the ropes of the Redcord system. Redcord Stimula system allows simple control of required intensity, frequency and duration of vibration. The vibration frequency can be selected in three stages, according to turning of individual motors. The green stage is designed for treatment of pain in head region and cervical spine, the orange and red stages are designed for treatment of low back and lower limbs.

The exercise unit included a total of 7 exercises adapted for use in the Redcord suspension system. Using the Redcord Stimula system to affect the low back area, strong ropes on which lower extremities were hung were placed on the vibrating component. The vibration frequency of $20 \mathrm{~Hz}$ was selected. This frequency was chosen based on the principle that low frequency affects a motor muscle output and a level of local proprioception. The Redcord Stimula device was set to red, the stimulating level - this level is used for a muscle stimulation and for an increasing the level of a local proprioception (Lundeberg, Nordemar, \& Ottoson, 1984). The degree of stretching of the elastic ropes with a hanging waist belt located at the pelvis of the subject was chosen according to the functional capabilities of the individuals, i.e. so that the subject could master a given number of repetitions without pain and without muscle tremor. Each exercise was carried out in three sets of eight repetitions.

During the therapy, each subject was led by a therapist so that the exercises were carried out without the above-mentioned mistakes, pain, muscle tremors and associated auxiliary movements. The number of exercises and sets were gradually increased until the completion of all the exercises in three sets in one training unit was reached. The increase in the number of exercises was influenced by the current condition of each subject. The therapy was conducted regularly twice a week.

\section{Statistical analysis}

Statistical data processing was carried out in Statistica (Version 10; StatSoft, Tulsa, OK, USA). In the case of the parameters obtained from questionnaires and measurements of pressure algometry, mean and standard deviations were calculated. The Wilcoxon nonparametric test, chosen due to the low number of subjects in the study, was used to compare the values obtained from the initial and final examination. The level of statistical significance was determined as $\alpha=.05$. The differences in initial and final evaluation of tests on the functional state of deep spinal stabilization system were described only verbally.

\section{Results}

Our results showed significant differences before and after therapy in ODI, SF-MPQ, VAS, and pressure algometry (Table 1).

Visible changes in motion before and after therapy with the use of vibration were also recorded in tests for the deep stabilization system of the spine (diaphragmatic test and the flexion of the hip, knee and ankle joint test). In initial examination, in the case of 13 of the 14 subjects participating in the research insufficiency of the deep stabilization system was found. During the

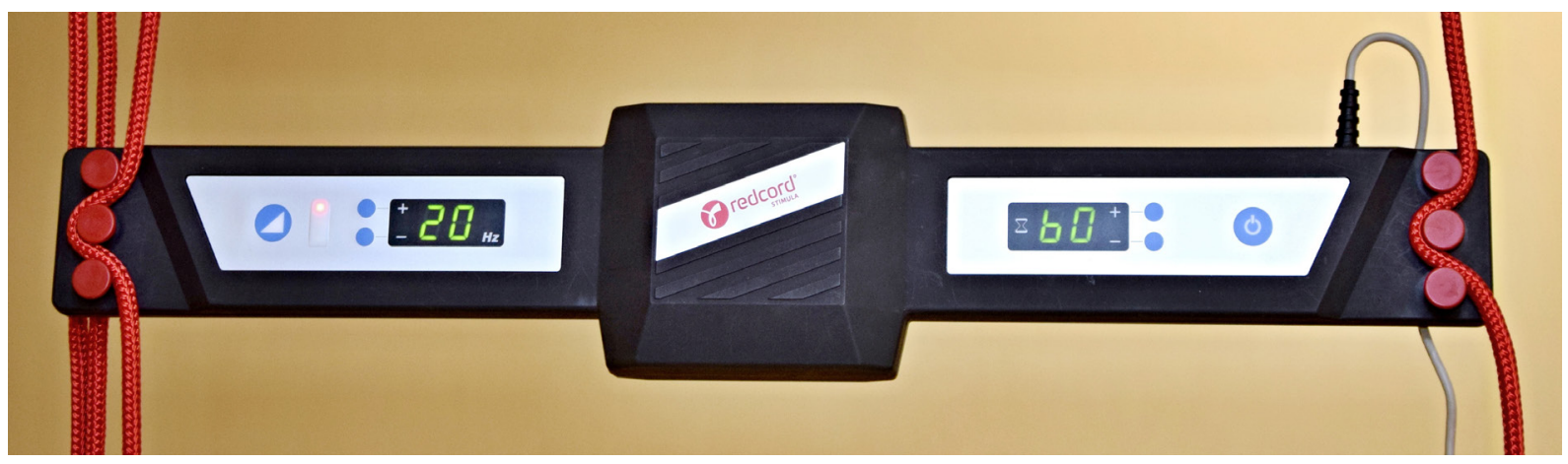

Figure 1. Redcord Stimula device. 
diaphragm test, the subjects failed to expand the chest in a lateral direction against the resistance, 10 of 14 subjects even failed to do so even in the case of mere palpation without resistance. Cranial migration of the ribs with the inability to maintain expiratory position occurred. During the flexion of the hip, knee and ankle joint test after removing the support of lower extremities, a predominance of activation of the upper part of $\mathrm{m}$. rectus abdominis occurred, mm. obliqui abdominis involvement was minimal. At the same time there was a setting of the chest to the inspiratory position and deepening of lumbar lordosis.

During the second examination, both tests on deep stabilization system were re-evaluated. In the evaluation of the diaphragm test, chest expansion in the lateral direction could be detected in the case of all subjects and the subjects were able to keep the chest in exhalation position, in the case of contradicted palpation, however, the cranial migration of the ribs and lateral chest expansion had ceased. Mm. obliqui abdominis were involved in function more when testing the flexion of the hip, knee and ankle joint test. The subjects were able to keep the expiratory chest setting.

\section{Discussion}

The influence of vibrations on the human body is dealt with in a large number of studies. The first studies devoted to vibration pointed out rather the negative effect of vibrations associated with the damage to soft tissues, joints or bones. For example, the study by
Bogadi-Sare (1993) also showed that exposition to a whole-body vibration may lead to the damage of spine, especially the lumbar part. Other studies, namely from the working environment, assess vibrations as a risk factor, especially the vibrations transferred to hands. These are local vibrations generated by working tools and machines. Kučera and Hlaváč (2011) describe the transmission of the vibration through upper extremities which are tempered poorly due to the muscle activity and are transmitted to wrist, forearm and arm. Longterm exposure to excessive vibration in working process leads to a more intensive damage to bones, joints, tendons and muscles. Along with this damage, there can also occur a damage to the blood-vessel system presenting itself as a professional traumatic vasoneurosis and damage to nerve tissues - entrapment syndromes and peripheral nerve damage (Pavlů \& Strachotová, 2011; Williams, 1975).

There are also some studies claiming that the effect of vibration on a human body is negligible or controversial (Blottner et al., 2006; van Nes et al., 2006).

At present, on the other hand, the studies describing the positive effects of local or regional vibrations on the human body appear (Muceli et al., 2010; Roy, Hollins, \& Maixner, 2002). These studies evaluate the application of so-called controlled vibrations to human musculoskeletal system. According to the Norwegian authors the application of local or regional vibrations increase proprioceptive central nervous system inputs, increase activity of vibrated muscle (Lundeberg, Nordemar, \& Ottoson, 1984), increase muscle strength

Table 1

Results of pain assessment at the baseline and after the treatment

\begin{tabular}{|c|c|c|c|c|c|}
\hline & \multicolumn{2}{|c|}{ Mean $\pm S D$} & \multicolumn{2}{|c|}{ Difference } & \multirow[b]{2}{*}{$p$} \\
\hline & Baseline & Post-treatment & Absolute & In \% & \\
\hline ODI (\%) & $21.39 \pm 11.73$ & $13.83 \pm 11.71$ & 7.56 & 35.34 & .001 \\
\hline \multicolumn{6}{|l|}{ SF-MPQ } \\
\hline Somatic component & $7.21 \pm 3.59$ & $2.00 \pm 1.17$ & 5.21 & 72.26 & .001 \\
\hline Emotional component & $4.00 \pm 2.90$ & $0.43 \pm 1.08$ & 3.57 & 89.25 & .002 \\
\hline Total score & $11.21 \pm 6.05$ & $2.42 \pm 1.91$ & 8.79 & 78.41 & .001 \\
\hline Visual Analog Scale (mm) & $41.92 \pm 19.87$ & $11.85 \pm 7.78$ & 30.07 & 71.73 & $<.001$ \\
\hline \multicolumn{6}{|l|}{ Pressure algometry $\left(\mathrm{N} / \mathrm{cm}^{2}\right)$} \\
\hline $\mathrm{L} 1$ vertebra & $33.90 \pm 11.59$ & $45.83 \pm 12.32$ & 11.93 & 35.19 & .005 \\
\hline $\mathrm{L} 2$ vertebra & $34.00 \pm 13.32$ & $46.58 \pm 12.60$ & 12.58 & 37.00 & .007 \\
\hline L3 vertebra & $39.58 \pm 14.93$ & $53.00 \pm 29.81$ & 13.42 & 33.90 & .049 \\
\hline L4 vertebra & $44.89 \pm 21.29$ & $52.11 \pm 18.50$ & 13.42 & 29.90 & .260 \\
\hline L5 vertebra & $51.10 \pm 20.87$ & $54.30 \pm 23.63$ & 3.20 & 6.26 & .646 \\
\hline
\end{tabular}

Note. $\quad$ ODI = Oswestry Low Back Pain Disability Questionnaire; SF-MPQ = Short Form McGill Pain Questionnaire. $p$-values $<.05$ are printed in bold. 
(Muceli et al., 2010) and decrease pain intensity (Roy, Hollins, \& Maixner, 2003).

Reduction in pain intensity, either by physiotherapy or medicaments by $30-35 \%$ is clinically considered a significant outcome, pain reduction of $45-50 \%$ is considered a very significant outcome of the therapy and thus a clear success of the prescribed pain therapy (Vepřková \& Opavský, 2009). The results in our study show a decrease of overall pain in the SF-MPQ by $78.4 \%$, the level of somatic component decreased by $72.3 \%$ and emotional component of pain decreased by $89.2 \%$. The value of VAS dropped by $71.7 \%$ at the output of the examination. According to the knowledge of the above-mentioned studies, this is a highly significant results of the therapy.

During the initial examination was average value ODI $21.4 \%$ and ranged in moderate disability. In the final examination, the value was $13.9 \%$ and was at the level of minimal disability. The similar results were obtained in the study of Pozo-Cruz et al. (2011). They evaluate the data from the ODI questionnaire after completing 12 -week therapy using whole body vibration. The value in initial examination was $26.5 \%$ and in final examination $20.3 \%$.

In the study were evaluated only the points from the more painful side of the spine. Pressure algometry values increased from L1 $\left(33.9 \mathrm{~N} / \mathrm{cm}^{2}\right)$ to L5 $\left(51.1 \mathrm{~N} / \mathrm{cm}^{2}\right)$. This increase in values was confirmed by studies by Giesbrecht and Battie (2005) who measured higher pressure algometry values in the L5 area than in comparison with the L3 area. The pressure algometry values were also higher in the final examination. Increasing the pressure algometry values means decreasing the intensity of the pain. This claim is supported by the results of the Giesbrecht and Battie (2005) study, where their results showed that higher values of pressure algometry in the L3 and L5 area are measured in painless subjects than in subjects with chronic low back pain.

Outside the objective results, even the subjects themselves subjectively perceived vibration as beneficial. It was only their subjective feeling of the effect of vibrations, without a scientific verification. After the first treatment, they consistently reported a feeling of lightness and relief in the low back area, pelvis and lower extremities, some even described ease when walking. After completion of the therapy, the subjects reported that they are able to perceive the location and setting of the pelvis better for example when sitting and standing. These claims could be explained by the basic principle vibration effect according to Norwegian physiotherapists - vibration increases the level of proprioception in vibration area.
The duration of rehabilitation by one patient with an initial and final examination and eight series of therapies took approximately 5 weeks. Each treatment lesson lasted for one hour, the initial and final examination lasted for two hours. It was very time consuming. The limitation of this study was the small observed group suitable for the study.

It would be effective to continue in research of the effect of regionally applied vibration to decrease pain in the low back, focusing on time data (rate of onset of the effect of therapy and the effect of the therapy with a duration).

\section{Conclusion}

The results of this study showed that local vibration has positive effects on the vibrated area of human body. It has been proven that the application of vibrations leads to a reduction of pain and to an improving the quality of a movement.

Decreasing the level of low back pain and decreasing the level of disability ascertained from the questionnaires, increasing the limit of pain when measuring pressure algometry, and better-quality motion while testing the deep stabilization system of the spine give a positive view of the pain treatment using local vibrations.

\section{Conflict of interest}

There were no conflicts of interest.

\section{Acknowledgments}

The study was supported by the IGA UP under project no. FTK_2013_011.

\section{References}

Blottner, D., Salanova, M., Püttmann, B., Schiffl, G., Felsenberd, D., Buehring, B., \& Rittweger, J. (2006). Human skeletal muscle structure and function preserved by vibration muscle exercise following 55 days of bed rest. European Journal of Applied Physiology, 97, 261-271.

Bogadi-Sare, A. (1993). The effect of whole-body vibration: An unrecognized medical problem. Archives of Industrial Hygiene and Toxicology, 44, 269-279.

Burke, D., Hagbarth, K. E., Lofstedt, L., \& Wallin, B. G. (1976). The response of human muscle spindle endings to vibration of non-contracting muscles. Journal of Physiology, 261, 673-693. 
Giesbrecht, R. J., \& Battie, M. C. (2005). A comparison of pressure pain detection thresholds in people with chronic low back pain and volunteers without pain. Physical Therapy, 85, 1085-1092.

Kolář, P., \& Lewit, K. (2005). Význam hlubokého stabilizačního systému $\mathrm{v}$ rámci vertebrogenních obtiží [The importance of deep stabilizing system in vertebrogenic difficulties]. Neurologie pro praxi, 6, 270-275.

Kučera, I., \& Hlaváč, P. (2011). Hodnocení rizikových faktorů pracovního prostředí a nemoci z povolání [Evaluation of risk factors in the working environment and occupational diseases]. Praktický lékař, 91, 288-292.

Loewenstein, W. R., \& Skalak, R. (1966). Mechanical transmission in a Pacinian corpuscle. An analysis and a theory. Journal of Physiology, 182, 346-378.

Lundeberg, T., Nordemar, R., \& Ottoson, D. (1984). Pain alleviation by vibratory stimulation. Pain, 20, 25-44.

Muceli, S., Farina, D., Kirkesola, G., Katch, F., \& Falla, D. (2010). Reduced force steadiness in women with neck pain and the effect of short-term vibration. Journal of Electromyography and Kinesiology, 21, 283-290.

Opavský, J. (2011). Bolest v ambulantní praxi [Pain in ambulatory care]. Prague, Czech Republic: Maxdorf.

Pavlů, D., \& Strachotová, H. (2011). Terapie a trénink s využitím vibrací: Současný trend nebo účinný prostředek? [Therapy and training with vibrations: Acctual trend or effectives procedures?]. Rehabilitace a fyzikální lékařství, $18,138-144$

Pfeiffer, J. (2007). Neurologie v rehabilitaci [Neurology in rehabilitation]. Prague, Czech Republic: Grada Publishing.

Pozo-Cruz, B. D., Hernández Mocholí, M. A., Adsuar, J. C., Parraca, J. A., Muro, I., \& Gusi, N. (2011). Effects of whole-body vibration therapy on main outcome measures for chronic non-specific low back pain: A single-blind randomized controlled trial. Journal of Rehabilitation Medicine, 43, 689-694.

Rittweger, J. (2010). Vibration as an exercise modality: How it may work, and what its potential might be. European Journal of Applied Physiology, 108, 877-904.

Rokyta, R., Kršiak, M., \& Kozák, J. (Eds.) (2012). Bolest [Pain] (2nd ed.). Prague, Czech Republic: TIGIS.

Roy, E. A., Hollins, M., \& Maixner, W. (2003). Reduction of TMD pain by high-frequency vibration: A spatial and temporal analysis. Pain, 101, 267-274.

Savre, I. (2011). Oswestry disability index - information booklet. Lyon, France: Mapi Research Trust.

Skála, B., Effler, J., Herle, P., \& Fila, P. (2011). Bolesti zad vertebrogenní algický syndrom 2011 [Back pain - vertebral algic syndrome 2011]. Prague, Czech Republic: Centrum doporučených postupů pro praktické lékaře.

van Nes, I. J. W., Latour, H., Schils, F., Meijer, R., van Kuijk, A., \& Geurts, A. C. H. (2006). Long-term effects of 6-week whole body vibration on balance recovery and activities of daily living in the post-acute phase of stroke. Stroke, 37, 2331-2335.

Vepřková, P., \& Opavský, J. (2009). Hodnocení bolesti a disability u pacientů s akutními a chronickými bolestmi dolní části zad [The assessment of pain and disability in patients with acute and chronic lower back pain]. Bolest, 12, 209-214.

Williams, N. (1975). Biological effects of segmental vibration. Journal of Occupational Medicine, 17, 37-39. 